\title{
Menophila: a poetic description of genital ambiguity in Hellenistic literature
}

\author{
Anastasia K. Armeni, ${ }^{1}$ Danai Georgakopoulou, ${ }^{1}$ Georgios K. Markantes, ${ }^{1}$ \\ Konstantina Barouti, ${ }^{1}$ Leonidas Liarakos, ${ }^{1}$ Vasiliki Vasileiou, ${ }^{2}$ Neoklis A. Georgopoulos ${ }^{1}$
}

${ }^{1}$ Division of Reproductive Endocrinology, Department of Obstetrics and Gynecology, University of Patras, Medical School, Patras, Greece; ${ }^{2} 1^{\text {st }}$ Department of Endocrinology, Diabetes Centre, "Alexandra" Hospital, Athens, Greece

Dear Sir,

In Ancient Greece, up to the Classical era, hermaphrodites were regarded as "monstrous" beings, messengers of evil or a sign of divine anger. They were consequently socially marginalized, being treated cruelly or even put to death.

As the centuries passed, tolerance towards these people gradually increased and in the Hellenistic era they were looked upon as simply amusing oddities of nature. Hence, they found a place in society, as depicted in the works of several writers of this period, such as Diodorus Siculus and Pliny the Elder. ${ }^{1}$

Key words: Menophila, Disorders of sexual development (DSD), Hermaphroditism, Male pseudohermaphroditism, Ambiguous genitalia, Androgen Insensitivity Syndrome (AIS), Testicular feminization

Address for correspondence:

Neoklis A. Georgopoulos, Department of Obstetrics and Gynecology, Division of Reproductive Endocrinology, University of Patras, Medical School, Rio-26500, Greece; Tel.: +30 2610-999835, Fax: +30 2610-993854,

E-mail: neoklisg@hol.gr

Received: 11-10-2017, Accepted: 17-10-2017

\section{TEXTUAL EVIDENCE SUPPORTING THE CASE OF MENOPHILA}

During the $2^{\text {nd }}$ century BC, a remarkable "female" named Menophila lived in Sardis, Asia Minor. She was renowned not only for her exceptional beauty but also for her ambiguous genitalia, her masculine personality and her promiscuous sexual practices.

The information we have on Menophila is derived mainly from three epigrams written by Marcus Argentarius, a Greek writer of the late Hellenistic period and included in the Anthologia Graeca.

The first (and most important) epigram is the following:

\section{"On the vices of Menophila \\ According to her/his fellow wantons, \\ so different is Menophila's body,}

Since she leaves no incontinence untested.

Rush and visit her Chaldaeans:

As her heaven ("cosmos") keeps hidden inside

Both Canis (the "dog") and the Gemini."2

This epigram is a genuine description of Menophila's genital ambiguity in the sophisticated, allegoric way for which Hellenistic literature is so famous. "Cosmos" is the equivalent of sky or heaven (Ovpavó in Greek). In the context of the epigram, "Cosmos" refers to the female genitalia (vulva). During summer, the main constellations appearing in the Aegean sky are the Dog (Canis Major, "Kúvas") and the Gemini 


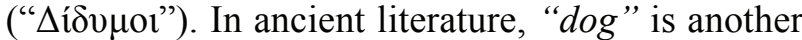
word for penis, whereas the term "gemini" or "twins" is used in many instances to imply the testes. This is indeed a very vivid metaphor using the view of the night sky to describe the peculiar appearance of Menophila's genitals.

The second epigram is as follows:

"When you were rich you were a lover, Sosicrates; being poor you love no longer. Such physic is in hunger. And Menophila, who used to call you her sweetness, her darling Adonis, now asks what your name may be..."

Here, Menophila's female identity becomes indisputable, as she is clearly described as a prostitute. It is well known that in Ancient Greece prostitution was practiced exclusively by beautiful women.

In the third epigram Marcus Argentarius underscores the diversity in the sexual practices of this person:

“...If you cherish desire for males' love,

Turn fair-hipped Menophila over and imagine That you hold a male menophilus in your embrace." 3

According to the above, Menophila was able to display both masculine and feminine sexual behaviors. She was a prostitute with a female external appearance but was able to equally satisfy males who preferred homosexual practices.

\section{MEDICAL INTERPRETATION OF MENOPHILA'S CASE}

From the available textual evidence, we may easily assume that Menophila had been assigned the female "social" sex and, hence, she had the physical appearance of a woman. Being a prostitute, ergo a beautiful woman, she must have had at least some breast development. Her external genitalia displayed both female and male phenotypic characteristics. The fact that she was able to perform sexually both as a male and a female implies that she possessed both a vulva with a vaginal opening and a penis-like structure which, in order to achieve penetration would more closely have resembled a juvenile phallus rather than an enlarged clitoris. Furthermore, Menophila is described as having two swellings ("gemini") close to her vulva, representing scrotum formation. Whether this included the presence of descended testes or was limited to an empty scrotum (unilateral or bilateral cryptorchidism) cannot be indisputably deduced from the available evidence. Nevertheless, the concurrent existence of a sexually functional penis makes the presence of adequate androgen action to permit testicular descent a far more possible scenario.

We can therefore conjecture that Menophila was a case of a disorder of sexual development (DSD), namely a person of a female appearance with ambiguous external genitalia characterized by a significant degree of virilization.

In general, the differential diagnosis of DSD includes virilizing tumors, gonadal dysgenesis, true hermaphroditism and male or female pseudohermaphroditism. Gonadal or adrenal virilizing tumors are usually of malignant origin and tend to be lethal unless resected, so they can be easily ruled out in our case. 46,XX DSD or female pseudohermaphroditism is also rejected due to the presence of testes, as is complete gonadal dysgenesis. ${ }^{4}$

A true hermaphrodite (ovotesticular DSD) possesses both ovarian and testicular tissue either in the form of bilateral "mixed" gonads (ovotestes) or as a combination of an ovary/ovotestis on one side and a testis/ovotestis on the other. As ovaries and ovotestes are exclusively intra-abdominal, the presence of bilateral scrotal gonads is impossible in ovotesticular DSD and thus it is also excluded, making male pseudohermaphroditism the only plausible diagnosis. ${ }^{4}$

Male pseudohermaphrodites (or 46,XY DSD) are incompletely androgenized males; they have testicles but the appearance of their external genitalia may range from micropenis and cryptorchidism to normal female genitalia. Defective androgen production or action is the cause and the degree of undermasculinization is determined by the extent of the defect.

As mentioned above, Menophila presented female secondary sex characteristics (breasts, etc), for which estrogen action is a prerequisite. In a male pseudohermaphrodite who lacks ovarian tissue, adequate amounts of androgens are necessary for breast development via aromatization to estrogens. The existence of a sexually functional penis and descended testes further strengthens the argument that in Menophila 
androgen production and action was partly but not completely defective.

Several enzyme deficiencies in the steroidogenic pathway could potentially lead to genital ambiguity. However, when compatible with life, they are either without breast development or with signs of heterosexual puberty (17-beta-hydroxysteroid dehydrogenase-HSD17B3 or 5a reductase genes). ${ }^{4}$

Of note, disorders of anti-Mullerian hormone $(\mathrm{AMH})$ and its receptor causing persistent Mullerian duct syndrome (PMDS) are easily ruled out, as they result in phenotypically normal males with cryptorchidism and intra-abdominal derivatives of the Mullerian duct.

Since none of the aforementioned enzyme defects in androgen production can adequately explain the phenotype in the case under review, a flaw in androgen action might be the culprit. Mutations in the androgen receptor (AR) gene cause a spectrum of disorders termed Androgen Insensitivity Syndrome (AIS). The degree of undermasculinization, and thus the phenotype, depends on the amount of residual receptor function, since testosterone and dihydrotestosterone are produced in normal amounts. In complete AIS (CAIS), AR is non-functional and patients are phenotypically female with external genitalia presenting absolutely no sign of virilization. CAIS could therefore not account for Menophila's appearance. $^{5}$

By contrast, partial AIS (PAIS) results from less severe AR mutations and the clinical presentation may range from mildly undervirilized male external genitalia (hypospadias and/or diminished penile size) to mildly virilized female external genitalia (clitoromegaly, slight labial fusion, significant shortening and blind ending of the vagina). In PAIS circulating testosterone is only partially active, whereas it is readily aromatized to estrogens. As in the mammary gland the estrogenic effect predominates over the androgenic, breast development is a usual corollary. ${ }^{5}$ Consequently, all the phenotypic characteristics as well as sexual ambivalence of Menophila can be explained in the context of PAIS.

In conclusion, we may assume that Marcus Argentarius' sophisticated epigrams did not represent an allegory but were instead based on a historical figure, a famous Sardian prostitute of the $2^{\text {nd }}$ century $\mathrm{BC}$, who most probably presented a case of partial Androgen Insensitivity Syndrome.

\section{REFERENCES}

1. Barouti K, Markantes GK, Armeni AK, Vasileiou V, Georgopoulos NA, 2017 The male bride: a story of Sexual Female-to-Male Transformation at marriage from the Hellenistic period, recorded by Phlegon of Tralles. Hormones (Athens) 16: 101-103.

2. Gow ASF, Page DL, 1968 The Greek Anthology: The Garland of Philip and some contemporary epigrams. Cambridge University Press, Cambridge.

3. Hubbard TK, 2003 Homosexuality in Greece and Rome - A sourcebook of basic documents. University of California Press, Berkeley and Los Angeles; p 296.

4. Hughes IA, Houk C, Ahmed SF, Lee PA, 2006 LWPES1/ ESPE2 Consensus Group. Consensus statement on management of intersex disorders. Arch Dis Child 91: 554-562.

5. Hughes IA, Davies JD, Bunch TI, Pasterski V, Mastroyannopoulou K, MacDougall J, 2012 Androgen insensitivity syndrome. Lancet 380: 1419-1428. 